\title{
Brasil: potência cordial? A diplomacia brasileira no início do século XXI
}

\author{
DOI: 10.3395/reciis.v4i1.344pt
}

\section{Carlos Vidigal}

Doutor em Relações Internacionais e professor de História da América da Universidade de Brasilia.

cvidigal@gmail.com

\begin{abstract}
Resumo
A política exterior brasileira e sua diplomacia conheceram um avanço significativo em seus conceitos, instrumentos e práticas no início do século XXI, o que corresponde a um novo padrão na inserção internacional do país, uma resposta aparentemente positiva diante da nova fase da globalização e caracterizada pela cordialidade. As relações internacionais do Brasil passaram nesse período por, pelo menos, quatro grandes mudanças: maior ênfase na internacionalização das empresas brasileiras, diversificação dos laços internacionais do país, atuação mais contundente nos organismos internacionais e a adoção do princípio da não-indiferença. Em seu conjunto, ao qual é possível agregar outros elementos, a política exterior brasileira revela o exercício de uma política de potência, sem que isso signifique a incorporação de valores e elementos do realismo clássico e do neorrealismo. Trata-se da construção de uma potência cordial, pretensamente cooperativa e moderna no plano internacional, porém incapaz de superar suas mazelas internas.
\end{abstract}

\section{Palavras-chave}

relações internacionais; política exterior brasileira; cooperação internacional; potência; não-indiferença
Pode uma potência ser cordial? A literatura realista das relações internacionais responderia, sem exitação, negativamente à questão proposta. O realismo clássico consolidou como fontes de poder - e base para a construção da potência - os recursos econômicos do país, as forças armadas e a capacidade de formar a opinião ou, em outras palavras, de construir um arcabouço político-ideológico e estabelecer consensos por meio dele (CARR, 2001). O neorrealismo, porquanto reconheça a importância de outros atores no cenário internacional, como as empresas, as organizações internacionais, as não-governamentais e mesmo os indivíduos, não se afasta de sua origem, qual seja, o Estado como principal ator no jogo internacional e a força militar e econômica como suas principais armas. A cordialidade é bem vista no exercício cotidiano da diplomacia, mas está longe de representar um recurso relevante de poder.

As perspectivas pluralistas reconhecem a existência de diversos atores, valoriza o direito internacional público e o princípio pacta sunt servanda, além de considerar que o multilateralismo é o caminho que pode levar as relações internacionais a um patamar superior de diálogo, com regras aceitas por todos. A cordialidade, neste caso, é elemento importante no exercício diplomático, com a capacidade de dinamizar as negociações, porém a partir de uma convergência anteriormente existente. Na visão de Rosenau (2000), a convergência se dá em torno de regras, procedimentos e acordos internacionais consensualmente estabelecidos por dois ou mais Estados, o que permite que se fale da existência de uma governança global. A governança é um fenômento mais amplo do que governo, abrangendo instituições governamentais e mecanismos informais:

A governança é um sistema de ordenação que só funciona se for aceito pela maioria (ou pelo menos pelos atores mais poderosos do seu universo), enquanto os governos podem funcionar mesmo em face de ampla oposição à sua política. (...) Portanto, 
pode-se falar em governança sem governo - sem mecanismos regulatórios em uma esfera de atividade que funcione efetivamente mesmo que não tenha o endosso de uma autoridade formal (ROSENAU, 2000, p. 16).

A referência à aceitação de um sistema de ordenação pela maioria inclui certamente a cordialidade, mas esta não significa um pré-requisito para o sistema, pois, nesta perspectiva, o conflito de interesses é parte integrante do sistema e comporta atitudes não cordiais. Esta forma de interpretar a cordialidade na área diplomática está presente igualmente na visão construtivista das relações internacionais.

Alexander Wendt, expoente da corrente construtivista, definiu essa perspectiva teórica como uma teoria estrutural do sistema internacional, com as seguintes características: os Estados devem ser a unidade principal de análise do sistema internacional; as estruturas-chave no sistema de Estados são mais intersubjetivas que materiais; e os interesses e as identidades dos Estados são construídos pelas estruturas sociais, pela natureza humana e pela política doméstica (WENDT, 1994). Em sua visão, o que importa não são os fatos como a distribuição da riqueza material entre os Estados, e sim sua interpretação e significado dado pelos próprios agentes. Se aplicarmos tais idéias à política exterior brasileira, pode-se afirmar que a visão de mundo dos brasileiros e os valores tradicionais de sua política exterior influenciam fortemente as atuais diretrizes internacionais do país, o que não é uma exclusividade brasileira. Tal vínculo seria comum às mais diferentes nações, inclusive os Estado Unidos da América.

A política exterior norte-americana nutriu-se - e continua a nutrir-se - do que alguns teóricos denominam soft power, a capacidade que possuem os dirigentes de Washington de construir consensos no plano internacional e que dialoga diretamente com o conceito gramsciano de hegemonia.

(...) a universalidade da cultura de um país e sua capacidade de estabelecer um conjunto de normas e instituições favoráveis que governem setores de atividade internacional são fontes decisivas de poder. Os valores da democracia, da liberdade pessoal, na mobilidade social e da abertura, frequentemente expressos na cultura popular americana, a instrução superior e a política externa contribuem com o poder do nosso país em muitas áreas (NYE JR, 2002, p. 37).
O soft power estadunidense não se confunde com a cordialidade da diplomacia brasileira, pois, além da maior abrangência, é reconhecido como importante fonte de poder e aplicado de forma sistemática em suas negociações internacionais. Em outras palavras, a cultura norte-americana é parte constituinte de sua política comercial, de seus investimentos, de suas intervenções armadas. A cordialidade brasileira, diferentemente, vincula-se mais a uma forma de conduzir a política exterior que a uma essência. Cordialidade, entretanto, não significa apenas boas maneiras e trato afável.

Recorre-se aqui a Sérgio Buarque de Holanda e seu clássico Raízes do Brasil, obra em que abordou o tema da cordialidade brasileira - aplicado não às relações internacionais do país, mas às práticas sociais e políticas. Para Holanda, o homem cordial age a partir dos sentimentos que brotam diretamente do coração, sem a mediação da racionalidade, tratando de maneira diferenciada amigos e adversários, e limitando o espaço para o funcionamento de normas e regras abstratas. Nesse sentido, a cordialidade conspira contra a burocracia e a democracia (WEGNER, 2009, p. 217).

Não seria justo acusar a diplomacia brasileira e as diretrizes de política exterior de atuar em sentido contrário aos valores e às regras da democracia, mesmo porque nesse ponto a noção de cordialidade aplicada à política exterior se afasta de Sérgio Buarque de Holanda. A Chancelaria brasileira preza a competência técnica, o diálogo internacional e seus foros. No entanto, deve-se reconhecer que tanto a diplomacia presidencial de Fernando Henrique Cardoso quanto o personalismo de Luís Inácio Lula da Silva buscaram o diálogo informal, as relações pessoais fluidas com grandes autoridades internacionais, o discurso diplomático simpático às causas sociais, ambientais e da paz. Tal comportamento - talvez mais movido pela paixão que pela razão - encobre algumas das grandes contradições da política exterior brasileira: país signatário dos mais importantes instrumentos jurídicos internacionais de defesa dos direitos humanos, de proteção ao meio ambiente, de combate aos ilícitos internacionais e de defesa da solução pacífica de controvérsias, apresenta dificuldades extremas no sentido de equacionar, internamente, violações aos direitos humanos, agressões ao meio ambiente e combate ao tráfico de armas e de drogas, por exemplo.

Embora se reconheçam alguns avanços nessas áreas, do ponto de vista político interno, o caminho a ser percorrido é longo e sinuoso. Em contrapartida, a política exterior 
brasileira, sob o governo Lula da Silva, tem dado mostras de agressividade em áreas como as negociações na OMC, a oposição à Alca (que praticamente caiu no esquecimento) e a busca da diversificação de mercados e de promoção das empresas brasileiras no exterior. Seria, nesse sentido, a cordialidade uma parte essencial de um soft power brasileiro, como sustentáculo da maior projeção internacional do país nos últimos anos? O propósito do presente texto é tentar responder, de maneira preliminar, a essa e outras questões vinculadas à ação da diplomacia brasileira no atual governo.

\section{Acumulado histórico e cordialidade}

O conceito de acumulado histórico, aplicado à política exterior brasileira, foi desenvolvido por Amado Luiz Cervo no livro por ele organizado O desafio internacional (CERVO, 1994). Após explicitar que na área de Relações Internacionais no Brasil há um pensamento sem teoria, ou seja, que diferentemente da academia inglesa ou norte-americana, no Brasil não desenvolvemos a teorização em relações internacionais, o que não é, em si, um elemento negativo, Cervo procurou explicitar os princípios e valores inerentes à política exterior, formadores de um determinado padrão de conduta da diplomacia brasileira. Como parte do acumulado histórico da política exterior brasileira identificou o pacifismo, o juridicismo, o realismo (que, com o tempo, tornou-se pragmatismo) e o desenvolvimento econômico como vetor.

Os padrões de conduta da diplomacia brasileira exercem pelo menos duas funções: dão previsibilidade à ação externa e moldam as políticas exteriores dos governos, impondo-se à sua sucessão e mesmo à mudança de regime político. $\mathrm{Na}$ atualização feita em torno do acumulado histórico da política exterior brasileira foram identificados nove elementos, a saber: a) autodeterminação, não-intervenção e solução pacífica de controvérsias; b) juridicismo; c) multilateralismo normativo; d) ação externa cooperativa e não-confrontacionista; e) parcerias estratégicas; f) realismo e pragmatismo; g) cordialidade oficial no trato com os vizinhos; h) desenvolvimento como vetor; i) independência de inserção internacional (CERVO, 2008, p. 26-31).

Entre os elementos do acumulado histórico brasileiro que se aproximam da noção de cordialidade estão a solução pacífica de controvérsia, a ação externa cooperativa e nãoconfrontacionista e a cordialidade oficial no trato com os vizinhos. Sustentada pelo pacifismo da sociedade brasileira, a solução pacífica de controvérsias dialoga com a convivência das diferenças na sociedade brasileira, que sugere a coexistência entre nações de diferentes culturas. A ação externa cooperativa e não-confrontacionista tem como histórico o "alinhamento ao Ocidente" à época das duas grandes guerras e como princípio a convicção de que a cooperação internacional é o melhor caminho para o desenvolvimento econômico e tecnológico. A não-confrontação se evidencia historicamente nas relações do Brasil com os Estados Unidos, que podem apresentar momentos de tensão e conflitos pontuais, mas jamais o confronto. Quanto à cordialidade no trato com os vizinhos, segundo Cervo, é um padrão de conduta concebido no século XIX, pelo Visconde, e, no século XX, pelo Barão de Rio Branco, vinculado à idéia da implementação da amizade e de desenvolvimento dos negócios, como instrumentos para a manutenção da paz.

A cordialidade oficial aconselha conduta regional que não ostente a grandeza nacional e a superioridade econômica e que elimine gestos de prestígio, mas que se guie pela realização dos interesses do Brasil sobre os dos vizinhos, seja pela cooperação seja pela negociação, e fortaleça seu poder internacional, razões que podem momentaneamente quebrar a cordialidade. A quebra não é aconselhável, por tal razão o governo Lula recusou-se a abrir conflito com seus colegas da Argentina e Bolívia, Néstor Kirchner e Evo Morales, quando interesses do comércio exterior e dos investimentos brasileiros foram afetados (CERVO, 2008, p. 30).

A cordialidade no trato com os vizinhos, sustentada essencialmente pela realização dos objetivos do país no largo prazo, pode ser aplicada igualmente à Venezuela sob Hugo Chávez, objeto de grande discussão na sociedade e no parlamento brasileiro. Os que se limitam a destacar os elementos autoritários do governo de Hugo Chávez e que pedem o afastamento em relação à Venezuela ignoram não apenas os excelentes resultados que o Brasil obteve junto àquele país, tanto no plano comercial quanto nos investimentos diretos, mas também o fato de que o afastamento nada traria de positivo. A cordialidade oficial evita desgastes desnecessários para a diplomacia brasileira e permite que maior atenção seja prestada na negociação de pontos substanciais de acordos.

Há, portanto, uma cordialidade que se faz presente nas relações com os vizinhos, e que se estende, em situações específicas, à solução pacífica de controvérsia e à ação externa cooperativa e não-confrontacionista. É a cordialidade oficial. Haveria, ao lado desta, outras manifestações de cordialidade, mais vinculadas ao impulso do coração que ao cálculo estratégico? 
Visões pouco condescendentes ao governo Lula da Silva e sua política exterior já estavam presentes nos primeiros anos de governo. Uma das principais críticas foi desferida contra a busca de novas parcerias estratégicas ou pelo menos à maneira pela qual o Itamaraty a orientou. Diante das dificuldades em fazer avançar, internamente, seus programas de governo, Lula da Silva teria transferido para a política exterior o papel de dar credibilidade ao governo, aproveitando-se da fusão da bonomia presidencial com o profissionalismo do ministro Celso Amorim. Aos discursos do presidente Lula quanto à abertura de grandes oportunidades de negócios vinculadas à quase automáticas parcerias estratégicas com Rússia, Índia e China, a crítica respondeu com a pouca atenção dirigida aos negócios com os Estados Unidos. Segundo o embaixador Rubem Barbosa, um dos principais críticos da política exterior do governo Lula...

há uma preocupação com o futuro do relacionamento [com os Estados Unidos], em vista de uma percepção de 'imprevisibilidade' das ações do Brasil quando comparadas às de outros países - tradicionais, mas previsiveis - 'opositores' dos EUA, como a Rússia, Índia e China (Primeira Leitura, $n^{\circ} 29$, julho 2004).

Tais críticas se estendem aos dias de hoje e se revelam em certas ocasiões, como o debate travado no parlamento brasileiro em torno do ingresso da Venezuela no Mercosul ou na viagem que o Presidente do Irã - Mahmud Ahmadinejad - fez ao Brasil, em novembro de 2009, ocasião em que Lula defendeu o direito iraniano ao enriquecimento de urânio para uso pacífico. Na visão de Celso Amorim, o Brasil está apenas exercitando seu direito de dialogar com os mais variados países do mundo, independentemente de eventuais dificuldades que os Estados Unidos e outros tenham em dialogar com eles.

A cordialidade presente no diálogo com a Rússia e a China, com a Venezuela e a Bolívia, com o Irã e Israel não deve ser confundida com inépcia, voluntarismo ou ingenuidade, na medida em que ela dialoga com tradições da sociedade e da política brasileira presentes na Constituição do país. Deve-se recordar que o artigo $4^{\circ}$ da Constituição Federal estabelece os seguintes princípios norteadores das relações internacionais do Brasil: independência nacional, prevalência dos direitos humanos, autodeterminação dos povos, não-intervenção, igualdade entre os Estados, defesa da paz, solução pacífica dos conflitos, repúdio ao terrorismo e ao racismo, cooperação entre os povos para o progresso da humanidade e concessão de asilo político. Como parágrafo único, o dispositivo que afirma o interesse do Brasil na integração regional e na formação de uma comunidade latino-americana de nações. A cordialidade permeia vários desses princípios e contribuiu para tornar o Brasil um país pacifista, democrático e comprometido com o direito humanitário. Pelo menos em termos oficiais.

\section{Os três dês da política exterior do governo Lula}

A política exterior do governo Lula da Silva pode ser sintetizada, em linhas gerais, no trinômio desenvolvimento, democracia, diversificação, esta última utilizada em, pelo menos, dois sentidos, o da busca de novas parcerias econômico-comerciais e o da participação ativa do Brasil na construção de novos foros internacionais, ou, no dizer do Itamaraty, novos mecanismos regionais, como o lbas, o G20 comercial e o Bric. A cordialidade, como elemento da diplomacia nacional, impulsiona essas diretrizes que formam parte da identidade internacional do Brasil.

Celso Lafer definiu como elementos da identidade internacional do Brasil: a nossa vizinhança; a inserção do Brasil, na condição de potência média de escala continental, no eixo assimétrico do sistema internacional; as constantes grocianas da política exterior brasileira; e a busca do desenvolvimento "do espaço nacional", por meio do nacionalismo de fins e da diplomacia da inserção controlada no mundo (LAFER, 2001). Converge dessa forma com Amado Luiz Cervo e seu conceito de acumulado histórico, no qual estão presentes o desenvolvimento como vetor, os princípios grocianos (juridicismo, solução pacífica de controvérsias, autodeterminação) e a necessidade da diversificação.

O desenvolvimento econômico, na visão de Cervo, tornouse vetor da política exterior do Brasil na década de 1930 e, com alguns percalços, como a onda neoliberal da década de 1990, se estende aos dias de hoje. Para Lafer, a Revolução de 1930 é um verdadeiro divisor de águas na história política, econômica e cultural brasileira e levou a um aprofundamento crítico sobre o nacionalismo brasileiro, por meio da noção do Brasil como país subdesenvolvido. Tal pensamento ganhou força nas décadas de 1950 e 1960 e traduziu-se no princípio de autonomia em política interna e exterior e na percepção de que a função precípua da chancelaria brasileira é identificar no cenário internacional quais recursos externos podem ser mobilizados para atender ao imperativo interno do desenvolvimento. Tal processo alcançou as últimas décadas, transitando da autonomia pela distância (distanciamento relativo do país na década de 1970) para a autonomia pela participação (multilateralismo da década de 1990).

No que tange ao eixo assimétrico do sistema internacional, creio, com Gelson Fonseca Jr., que se antes o país construiu, com razoável sucesso, a autonomia 
possível pelo relativo distanciamento em relação ao mundo, nesta virada de século esta autonomia possível, necessária para o desenvolvimento, só pode ser construída pela participação ativa na elaboração de normas e pautas de conduta da gestão da ordem mundial (LAFER, 2001, p. 117).

A despeito das distintas percepções quanto à natureza e à qualidade dos governos de Cardoso e de Lula da Silva por parte de Cervo e Lafer, percepções muitas vezes antagônicas, há uma convergência em torno da tradição diplomática brasileira, de seus valores essenciais e de da conduta da diplomacia brasileira. Convergência também há quanto à inevitabilidade da globalização e de uma inserção internacional mais ativa na mesma, quanto aos valores da democracia aplicados ao jogo internacional e quanto à diversificação dos laços internacionais do Brasil.

A democracia brasileira, embora descontinuada na trajetória do país no século XX e questionável em seus elementos essenciais, foi identificada como princípio basilar da política exterior brasileira pelo diplomata e acadêmico Alexandre Parola. Na obra A ordem injusta, Parola propõe o conceito de pragmatismo democrático para definir a política exterior do governo Lula da Silva, "uma política que articula a promoção de valores inspirados pela própria cidadania com a capacidade de atuar de modo não dogmático em defesa dos interesses nacionais e da construção de uma ordem justa" (PAROLA, 2007, p. 30). A noção de ordem em relações internacionais, assim como os conceitos de poder e de justiça, é, na visão desse autor, essencialmente relacional, pois uma ordem refere-se a posições relativas dentro de um sistema. A crítica brasileira à ordem internacional injusta pauta-se, assim, na noção de justiça, pois aos países sem excedentes de poder, a solidez da construção conceitual organizada em torno de valores é um importante instrumento para a ação diplomática.

O desenvolvimento socioeconômico do país foi a tônica do discurso de posse de Luiz Inácio Lula da Silva na Presidência da República, em $1^{\circ}$ de janeiro de 2003. As negociações na Alca, no Mercosul, junto à União Européia e nos foros multilaterais e bilaterais deveriam refletir a preocupação com a elevação da renda e a geração de empregos, traduzida na dinamização do comércio exterior, na obtenção de tecnologias avançadas e na busca de investimentos produtivos. As principais diretrizes da política exterior deveriam agir em favor da renda e de empregos para os brasileiros. Entre seus diversos objetivos foram destacados o combate ao protecionismo dos países desenvolvidos, a democratização das relações internacionais sem hegemonias de qualquer espécie e a prioridade dada à América do Sul e ao Mercosul no sentido da construção da integração, com base em ideais democráticos e de justiça social (LULA DA SILVA, 2003).

Depreendia-se do discurso que o Brasil buscaria maior protagonismo nas relações internacionais, rejeitando hegemonias de qualquer espécie, com base nos ideais democráticos e da justiça social, em franco diálogo com a tradição autonomista da política exterior brasileira. O Brasil apresentava-se como potência em construção, porém de forma diferente das potências emergentes do passado, cujas principais fontes de poder foram invariavelmente a capacidade produtiva e financeira, as forças armadas e a ideologia e/ou seu estilo de vida. Na visão de Parola, ao determinar o papel da democracia, o presidente Lula da Silva teria promovido uma alteração significativa.

Sob a égide conceitual de uma política externa definida, no mais alto nível, como orientada pela democracia, abriga-se a convicção de que uma ordem internacional pautada por valores é a que mais amplas possibilidades oferece, não apenas para a promoção dos interesses nacionais de uma potência média com as características do Brasil, mas também para a própria estabilidade sistêmica (PAROLA, 2007, p. 422).

Não por acaso, Lula da Silva, em seu discurso de posse referiu-se à ação diplomática do Brasil, como orientada por uma perspectiva humanista, tendo por principal objetivo o desenvolvimento nacional. Na perspectiva de Parola, uma política externa orientada por valores e voltada para a construção de uma ordem internacional mais justa deve incorporar a defesa de maior igualdade, deve promover o papel da democracia e não pode abrir mão do papel essencial do Estado democrático como mediador de tensões e divergências. Ao Estado democrático é atribuída a legitimidade e representatividade para falar em nome da sociedade e proceder à defesa de valores como os direitos humanos, o meio ambiente e o combate à criminalidade. Lula da Silva, diferentemente de Cardoso, incorporou mais decididamente a democracia como princípio orientador da política exterior brasileira.

Se Parola destacou uma mudança basilar na política exterior de Lula da Silva, Tullo Vigevani e Gabriel Cepaluni identificaram mais as continuidades que as mudanças, embora reconheçam algumas novidades importantes. Para Vigevani e Cepaluni, da mesma forma que não houve ruptura significativa com paradigmas históricos da política externa do Brasil, e sim desdobramentos ou reforços de ação, houve 
uma mudança nas ênfases dadas a certas opções abertas anteriormente. Ambos os governos, como representantes de tradições diplomáticas distintas, apresentaram diferenças nas ações, nas preferências e nas crenças, mas buscaram não se afastar de um objetivo sempre perseguido: o desenvolvimento econômico, com autonomia política (VIGEVANI \& CEPALUNI, 2007). Na visão desses autores, a busca de uma relação de "amizade" com os Estados Unidos e uma estratégia de "autonomia pela participação" são marcas que nos remetem às escolas diplomáticas de Rio Branco e de Osvaldo Aranha. Já a idéia de que se deve defender a soberania e os "interesses nacionais", mesmo criando potenciais conflitos com os Estados Unidos, é clara na tradição da "política externa independente", de San Tiago Dantas.

Vigevani e Cepaluni partiram da hipótese que diferentemente do governo Cardoso - que adotara a idéia da "autonomia pela participação", em contraponto à "autonomia pela distância" dos últimos presidentes militares - o governo Lula da Silva procurou inserir o Brasil no cenário mundial acentuando formas autônomas, diversificando os parceiros e as opções estratégicas. A "autonomia pela diversificação" teria (e tem) como principal característica a ênfase na cooperação Sul-Sul, percebida como instrumento para diminuir a vulnerabilidade do país diante das grandes economias. Nas palavras dos autores:

Definimos sinteticamente (...) autonomia pela diversificação como a adesão do país aos princípios e às normas internacionais por meio de alianças SulSul, inclusive regionais, e de acordos com parceiros não tradicionais (China, Ásia-Pacífico, África, Europa Oriental, Oriente Médio, etc.), pois acredita-se que eles reduzem as assimetrias nas relações externas com países mais poderosos e aumentam a capacidade negociadora nacional.

A ênfase de Vigevani e Cepaluni recaiu sobre as continuidades, diferentemente de Amado Luiz Cervo, que identifica uma ruptura substancial na passagem dos anos 1990 para os anos 2000: a mudança do paradigma neoliberal (ou do Estado Normal) para o paradigma do Estado Logístico. Cervo entende por Estado Logístico a unidade política que preserva sua autonomia decisória, adentra o mundo pela interdependência e implanta um modelo de inserção pósdesenvolvimentista. Seu escopo final seria a superação das assimetrias, a elevação do patamar nacional ao nível das nações avançadas (CERVO, 2008, p. 85-86). É o Estado que retoma alguns valores do nacional desenvolvimentismo, incorpora a crítica neoliberal ao mesmo e reconhece a força da economia globalizada.

Dessa forma, as três interpretações acima resumidas (CERVO-LAFER, PAROLA e VIGEVANI \& CEPALUNI) podem ser denominadas os três dês da política exterior brasileira - desenvolvimento, democracia e diversificação. Referemse a distintas dimensões da política exterior do país: a) ao objetivo da industrialização e do desenvolvimento econômico, fundado nas noções fornecidas pela economia política; b) ao princípio democrático como norteador da ação diplomática do país, em perspectiva grociana ou neogrociana; c) às estratégias desenvolvidas pelo governo Lula da Silva, diversificando parcerias comerciais e fluxos de investimento, em uma visão algo funcionalista. As três visões são úteis para o entendimento da política exterior brasileira atual e apontam para a ênfase muitas vezes atribuída à cooperação internacional, como instrumento para o desenvolvimento do país, às negociações multilaterais e ao respeito ao Direito Internacional Público e à diversificação dos interlocutores do país.

\section{Cooperação internacional: uma política cordial e solidária}

A cooperação internacional do Brasil é uma das formas mais visíveis de aplicação do que Parola se referiu como construção de uma ordem justa. As origens da cooperação internacional recebida pelo país remontam, pelo menos, ao segundo pós-guerra, orientada essencialmente para os projetos de desenvolvimento econômico do país. Posteriormente, na medida em que o Brasil se tornou uma das grandes economias industriais do mundo, ainda que em desenvolvimento, e abriu-se às forças da globalização, tornou-se também um prestador de cooperação.

A partir da década de 1990, ao lado da cooperação recebida, o Brasil passou a prestar cooperação em ritmo crescente, orientada em geral para países da África subsaariana e para os vizinhos da América Latina. A cooperação tornouse instrumento fundamental para a política externa brasileira, como observou Celso Amorim (FUNAG, 2007, p. 323). Com a integração da Agência Brasileira de Cooperação (ABC) à estrutura organizacional do Ministério das Relações Exteriores, a Agência passou a desempenhar um papel de grande importância para a aproximação do Brasil com outros países, notadamente os em desenvolvimento. Entre as áreas de atuação mais intensa da $A B C$ se destaca a de agricultura e educação (programas de alfabetização), responsáveis por 55\% 
da cooperação prestada pelo país, secundadas pelas áreas de formação de quadros técnicos, biocombustíveis (etanol e diesel), saúde (combate ao HIV/aids), apoio eleitoral (urnas eletrônicas), cooperação desportiva (futebol), entre outras. Segundo o Chanceler brasileiro, ao oferecer oportunidades de cooperação, o Brasil não almeja ganho ou lucro comercial, assim como nenhuma outra condicionalidade.

Segundo o discurso da $A B C$, a cooperação prestada se baseia em valores como a nova visão das relações entre países em desenvolvimento, inspirada na comunhão de interesse e na ajuda mútua. Tais princípios estiveram presentes no balanço realizado no final do ano de 2003, pelo embaixador Ruy Nogueira, por ocasião da Conferência de Alto Nível do G-77, em Marraqueche, Marrocos. A exposição sobre as principais iniciativas brasileiras destacou algumas áreas, sem a pretensão de uma listagem exaustiva. Em primeiro lugar, foram relatadas as iniciativas na área do ensino profissionalizante, os cursos de formação profissional, em parceria com o Serviço Nacional e Aprendizagem Industrial, o Senai. Várias ações já haviam sido realizadas em Angola, Timor Leste, Guiné Bissau, Cabo Verde e Paraguai (Hernandárias, região de Ciudad del Este). Na área do ensino fundamental, o Brasil havia disponibilizado sua experiência na estruturação dos programas Bolsa-Escola e Alfabetização Solidária, esta última incluindo a alfabetização de jovens e adultos. Entre os principais beneficiários, São Tomé e Príncipe e Moçambique. No Timor Leste, a ABC apoiou, a partir de 2002, o processo de reintrodução da língua portuguesa e o combate ao analfabetismo. Na América Central, El Salvador e Guatemala foram atendidos com iniciativas semelhantes.

Na área da saúde, em que a cooperação técnica brasileira tem sido muito demandada, um papel de relevância tem sido ocupado pelo Programa Saúde da Família. Um tema objeto de crescente demanda por parte de países latino-americanos e africanos é o de combate às doenças sexualmente transmissíveis, particularmente à aids (DST/aids). Diversos subprogramas nesta área atendem países como Guiné Bissau, Moçambique, Angola, Bolívia, Equador, Peru e Guatemala. Cuba e Botswana também foram atendidos com ações de amplo espectro, envolvendo intercâmbio de tecnologias para diagnóstico da infecção por HIV, capacitação de técnicos, gestão de programas etc.

Segundo Ruy Nogueira, alguns projetos de cooperação técnica buscam envolver todos os países interessados nas questões de saúde da região, como o projeto de Cooperação Tripartite Brasil-Peru-Colômbia em Saúde. Seu objetivo é melhorar as condições gerais de saúde na área da Amazônia divisada pelos três países e ameaçada por doenças como cólera, tuberculose, malária e febre amarela. Nesse mesmo sentido, o Brasil participa do projeto Fortalecimento da Capacidade de Vigilância e Controle Sanitário Integrado em Portos, Aeroportos e Fronteiras da Região BrasileiroColombiana. Destaque também coube às iniciativas na área de controle da mortalidade infantil, tema objeto de acordos de cooperação com Angola e Paraguai, além dos demais países platinos.

Na área de alimentação e agricultura, uma das três áreas de maior importância na cooperação prestada pelo Brasil, as ações objetivavam transferir as experiências brasileiras de desenvolvimento da agricultura tropical, introdução de novas tecnologias para a melhoria dos produtos e busca de maior produtividade do trabalho rural. Foram criados diversos projetos de cooperação nessa área, em países da América Latina, África e Timor Leste (NOGUEIRA, 2009). Na visão do embaixador, o Brasil ainda carecia de recursos humanos para almejar uma expansão mais significativa no setor.

A ausência de interesse material por parte do Brasil foi a tônica de pronunciamento do embaixador Ruy Nunes Pinto Nogueira, Subsecretário Geral de Cooperação e Promoção Comercial, em evento realizado no Rio de Janeiro nos dias 8 e 9 de outubro de 2009 (FUNAG/IPRI, 2009). Entusiasta da cooperação prestada pelo Brasil, Nogueira esclareceu que, apesar de o Brasil ser mais tomador que doador de cooperação, somente no governo Lula foram assinados 380 ajustes complementares, abrangendo programas nas áreas de saúde, agricultura, educação, biocombustíveis, desenvolvimento, informática, esportes, entre outros. A solidariedade brasileira foi exemplificada com o programa de cooperação com a Argélia, na área de cirurgia cárdio-vascular, cooperação desinteressada, embora o país venda alguns equipamentos médicos dessa área.

A solidariedade seria igualmente a única motivação para o desenvolvimento de projetos estruturantes, como o realizado no Haiti, envolvendo ações que vão da criação de uma fazenda modelo à vacinação em massa contra a rubéola. Na visão do embaixador Gonçalo de Barros Carvalho e Mello Mourão, Diretor do Departamento para a América Central e Caribe do MRE, o poder que Brasil apresenta no Haiti não é o poder das armas e sim o da solidariedade. No entanto, afirma que o Brasil não foi ao Haiti para vender têxteis, mas que não há problema em vender para eles; e que a melhor maneira de sair do Haiti - uma referência à Missão das Nações Unidas para a Estabilização do Haiti (Minustah) -, é lá permanecer. Contradições apenas aparentes, pois não há cooperação desinteressada, mesmo que de maneira difusa, e, no caso da Minustah, a estabilização do país é objetivo humanitário 
e, indiretamente, poderá contribuir para os negócios do Brasil na área do Caribe.

A tensão entre interesses e cooperação não é assunto novo na área de relações internacionais e certamente também se faz presente em outra área de cooperação internacional, a cooperação em ciência e tecnologia. No mesmo evento acima citado, o embaixador Hadil da Rocha Vianna, Diretor do Departamento de Temas Científicos e Tecnológicos do Itamaraty, explicitou sua satisfação com o atual nível alcançado pelo Brasil nessa área, embora o Brasil não possua uma política para transferência e aquisição de tecnologia. O Brasil é a $13^{\text {a }}$ potência mundial em termos de ciência e tecnologia, com investimentos que atingem 1,45\% do PIB, contra 3 a 4\% da Coréia do Sul e 8\% da China. Em áreas como biotecnologia, tecnologia da informação, metal-mecânico e outros o Brasil não mais aceita cooperação assistencialista e se orgulha com o fato de negociar de igual para igual, oferecendo cooperação técnica em troca de cooperação técnica.

O tema da cooperação prestada vincula-se, indubitavelmente, à construção da imagem da nação no exterior a imagem de uma potência cordial - e ao uso do soft power, ainda que de alcance limitado. O aumento da cooperação prestada pelo Brasil nas últimas décadas acompanhou o movimento de maior presença internacional do país, seja na área comercial, seja como exportador de capitais. Nesse sentido, a abertura do Brasil à globalização, após o duro aprendizado da década de 1980, promoveu uma readequação do acumulado histórico da política exterior aos novos tempos e elementos novos como a cooperação prestada.

\section{Brasil, potência cordial?}

A discussão em torno da possibilidade ou não da existência de uma potência cordial pressupõe o debate em torno da própria noção de poder. Um dos autores clássicos do realismo, Hans Morgenthau, partiu da idéia de poder aplicada ao indivíduo - a força de um homem sobre as mentes e as ações de outros homens - para indagar acerca do que queremos dizer quando atribuímos a uma nação aspirações e ações (MORGENTHAU, 2003, p. 200). Identificada a dificuldade de se atribuir a todos os cidadãos de uma nação determinados anseios, Morgenthau reconhece o nacionalismo moderno como uma das fontes para a construção do poder e sugere a geografia, os recursos naturais, a capacidade industrial, o grau de preparação militar, a população, a índole nacional (qualidades do intelecto e da índole que ocorrem com mais freqüência), o moral nacional (grau de determinação com que uma nação apóia as políticas externas de seu governo na guerra ou na paz), a qualidade da diplomacia e a qualidade do governo como os elementos constitutivos do poder nacional. Morgenthau tinha em mente os Estados Unidos do segundo pós-guerra e a construção da potência norte-americana.

A complexidade e sofisticação do raciocínio de Morgenthau são maiores do que seus críticos apresentam. A qualidade da diplomacia, embora de natureza instável, foi colocada como o mais importante entre todos os fatores que entram na formação do poder de uma nação, tomando a presença dos demais fatores como pré-requisito:

A qualidade da diplomacia de uma nação combina esses diferentes fatores em um todo integrado, confia-lhes direção e peso, bem como desperta potencialidades adormecidas, ao passar-lhes o sopro do poder real. (...) Trata-se (...) da arte de reunir os diferentes elementos do poder nacional, no intuito de fazer com que produzam o maior efeito possível sobre aqueles pontos na situação internacional que dizem respeito mais diretamente aos interesses nacionais (MORGENTHAU, 2003, p. 273).

No caso do Brasil contemporâneo, o Itamaraty não se cansa de exaltar, quando das negociações em torno da reforma do Conselho de Segurança das Nações Unidas, por exemplo, os recursos de poder do país, em especial a geografia, os recursos naturais, a população e a qualidade da diplomacia. Mais difícil é argumentar em torno da capacidade industrial, do grau de preparação militar, da índole nacional, da moral nacional e da qualidade do governo como os elementos constitutivos do poder nacional brasileiro. Este último aspecto já se fazia presente nas idéias de San Tiago Dantas, ao propor uma política exterior vinculada ao aprofundamento da democracia e à implementação de reformas sociais.

Ao se tomar como base a análise de Morgenthau, o Brasil e, com ele, o Itamaraty, ficam a meio caminho. A qualidade da diplomacia não pode chegar ao seu ponto ótimo se faltarem importantes recursos de poder como os acima referenciados. Ademais, se acrescentarmos a contribuição dos construtivistas, para os quais os interesses e as identidades dos Estados dos Estados são construídos, em grande parte, por suas estruturas sociais, de natureza intersubjetiva, o Brasil deveria se ocupar mais com a índole e com a moral nacional, ao lado da qualidade do governo, do que com a preparação militar, embora seja uma fonte imprescindível de poder. Em termos mais modernos, pode-se assinalar que o pacifismo e 
a democracia são instrumentos importantes na construção da potência e que não são incompatíveis com a boa preparação militar. Mais importante, porém, é a qualidade do governo, ou seja, um governo capaz de promover o equilíbrio entre recursos materiais e humanos e a política externa a ser implementada, de articular os diversos recursos disponíveis e de obter apoio popular à política exterior.

O apoio popular será mais consistente na medida em que a política exterior refletir valores aplicados inicialmente no âmbito interno, como, por exemplo, o desenvolvimento social e econômico, a democracia e suas instituições, o respeito à pluralidade da sociedade, a cooperação entre as diversas instâncias do poder (e da sociedade) nacional, a inclusão social. Uma das maiores críticas já realizadas à política exterior brasileira foi feita por Gerson Moura, ao assinalar a distância que tradicionalmente é guardada entre a formulação e implementação de nossa política exterior e os interesses da sociedade:

Essa perturbadora ausência/distância/exclusão das grandes maiorias na elaboração ou, pelo menos, na discussão e vigilância da política exterior brasileira, talvez seja menos a expressão da apatia das massas em relação aos problemas internacionais e muito mais à característica da relação dirigentes-dirigidos na experiência histórica nacional. A competência específica de nossas elites políticas na condução da política exterior, dada por sua vivência internacional, exibe uma notável continuidade no tempo: seu cosmopolitismo excludente constitui, no plano das relações internacionais, a cara moderna de um coração conservador. Assim foi, assim é, e, ao que tudo indica, assim será (MOURA, 1991, p. X)

Como pode ser cordial uma potência emergente que mantém nossos índices de analfabetismo, de pobreza, de violência e de exclusão? O Brasil ainda não chegou à condição de potência, mas é possível afirmar que está em processo de construção da potência. Nessa caminhada são elementos iniludíveis a preservação do acumulado histórico de sua política exterior, devidamente adequado à conjuntura internacional deste início de século XXI; as preocupações em torno do desenvolvimento, em seu sentido amplo; a defesa dos princípios democráticos, tanto externa quanto internamente; a diversificação dos laços internacionais do país, muitas vezes para além de barreiras doutrinárias; a construção de recursos de soft power, e, nele, o aprimoramento da cooperação e da cordialidade. A cordialidade, no entanto, é forma e não essência. Ela requer maior consistência nos demais recursos de poder.

\section{Referências bibliográficas}

CARR, E. H. Vinte anos de crise (1919-1939). Brasilia: Editora Universidade de Brasília; Instituto de Pesquisa de Relações Internacionais, 2001.

CERVO, A. L. O desafio internacional. Brasilia: Editora Universidade de Brasília, 1994.

CERVO, A. L. Inserção internacional: formação dos conceitos brasileiros. São Paulo: Saraiva, 2008.

DANTAS, S. T. Política externa independente. Rio de Janeiro: Civilização Brasileira, 1962.

FUNAG/IPRI. Seminário de Alto Nível sobre Política Externa, 8 e 9 de outubro de 2009, Palácio Itamaraty, Rio de Janeiro.

LAFER, C. A identidade internacional do Brasil e a política externa brasileira. São Paulo: Perspectiva, 2001.

LULA DA SILVA, L. I. Discurso do Senhor Presidente da República na Sessão de Posse, no Congresso Nacional. Brasília, Brasil, 01/01/2003. Disponível em: http://www.mre. gov.br. Acessado em: 26/10/2009.

LULA DA SILVA, L. I.; AMORIM, C.; GUIMARÃES, S. P. A política externa do Brasil. Brasília: IPRI/FUNAG, 2003.

MORGENTHAU, H. J. A política entre as nações: a luta pelo poder e pela paz. Brasília: Editora Universidade de Brasília: Instituto de Pesquisa em Relações Internacionais; São Paulo: Imprensa Oficial do Estado de São Paulo, 2003.

MOURA, G. Sucessos e ilusões: relações internacionais do Brasil durante e após a Segunda Guerra Mundial. Rio de Janeiro: Editora da Fundação Getúlio Vargas, 1991.

NOGUEIRA, R. N. P. Exposição das principais iniciativas brasileiras no âmbito da cooperação prestada pelo Brasil a outros países em desenvolvimento (apresentadas na Conferência de Marraqueche sobre Cooperação SulSul). Disponível em: http://www.braseuropa.be/CTB.htm. Acessado em: 13/12/2009.

NYE JR, J. S. O paradoxo do poder americano: por que a única superpotência do mundo não pode prosseguir isolada. São Paulo: Editora Unesp, 2002.

PAROLA, A. G. L. A ordem injusta. Brasília: Fundação Alexandre de Gusmão, 2007.

ROSENAU, J. N. Governança sem governo: ordem e transformação na política mundial. Brasília: Editora Universidade de Brasília; São Paulo: Imprensa Oficial do Estado, 2000. 
VIGEVANI, T.; CEPALUNI, G. A política externa de Lula da Silva: a estratégia da autonomia pela diversificação. Contexto Internacional, Rio de Janeiro, vol. 29, n 2, julho/dezembro 2007, p. 273-335.

WEGNER, R. Caminhos de Sérgio Buarque de Holanda. In:
BOTELHO, A.; SCHWARCZ, L. M. (org). Um enigma chamado Brasil: 29 intérpretes e um país. São Paulo, Companhia das Letras, 2009.

WENDT, A. Collective identity formation and the international State. Am. Pol. Sci. Rev. v.88, 1994. 